\title{
Urban and rural patterns of bicycle helmet use: factors predicting usage
}

Sande Harlos, Lynne Warda, Norma Buchan, Terry P Klassen, Virginia L Koop, Michael E K Moffatt

\begin{abstract}
Objectives-To document current bicycle helmet use in Winnipeg, Manitoba and nearby rural communities, and to identify target groups for a helmet promotion campaign.

Methods-Cyclist helmet use was observed between 28 May and 20 August 1996 at a sample of urban and rural locations. Age, gender, helmet use, riding companion(s), location type, correct helmet use, and use of headphones were recorded. Univariate and multivariate analyses were performed. Adjusted odds ratios with $\mathbf{9 5 \%}$ confidence intervals were calculated from the final models.

Results-Altogether 2629 cyclists (70\% male, 30\% female) were observed: 2316 at 183 urban locations and 313 at 25 rural locations, with nearly equal numbers of children and adults observed. Overall helmet use was $21.3 \%$, with lower use in males $(18.9 \%)$ than females $(26.3 \%)$, despite gender only being a significant variable on multivariate analysis for children under 8 years and adults. Urban helmet use was considerably higher $(22.9 \%)$ than rural use $(8.9 \%)$. Helmet use increased linearly as mean neighbourhood income increased, with a nearly fourfold difference in use between the highest and lowest income neighbourhoods. Children less than 8 years old and adults had the highest, and teenagers the lowest, use. Significant predictive variables were identified separately by age category to inform targeted programming.

Conclusions-We documented low helmet use in our region, emphasizing the need for a regional helmet promotion campaign as well as future helmet legislation. A marked urban-rural difference in helmet use that has not been previously reported was also identified. Target groups for a future campaign include adolescents, males, rural cyclists, and those in lower income neighbourhoods.

(Injury Prevention 1999;5:183-188)
\end{abstract}

Keywords: bicycle helmet use; socioeconomic status; rural; urban

Department of Paediatrics, University of Alberta, Edmonton, Alberta

T P Klassen

Correspondence to: Dr Harlos, Deputy Medical Health Officer (e-mail

sharlos@city.winnipeg.mb.ca). isolated and rural communities. In Manitoba, Canada, where a coordinated provincial pre-
After over a decade of successful bicycle injury prevention programs across North America, there remain large gaps in public awareness and preventive programming, particularly in vention program has yet to be implemented and helmet legislation has not been introduced, bicycle injury remains a significant health problem. In this province of 1.1 million residents, an average of 100 children and adolescents less than 20 years of age and 65 adults are hospitalized annually for cycling injuries, with children in rural areas experiencing a somewhat higher admission rate than urban children (unpublished data, Epidemiology Unit, Manitoba Health and Health Information Systems, Manitoba Health). There were 16 cycling deaths among Manitobans of all ages between 1991 and 1995 .

In studies of children treated in emergency departments for bicycle injuries, $4 \%-17 \%$ require admission to hospital ${ }^{2-8}$ and $6 \%-14 \%$ of these admissions require treatment in an intensive care unit. ${ }^{4-10}$ Head injury is the most common reason for admission, accounting for between one third and two thirds of all admissions. ${ }^{4} 9^{11-13}$ A study that followed up children injured in bicycle crashes suggests that significant and persistent neurological deficits are not uncommon. ${ }^{11}$

The effectiveness of helmet use $\mathrm{e}^{14-17}$ and community campaigns in preventing head and other injuries have been well documented. ${ }^{18} 19$ Helmet use has been estimated to reduce serious head injury by $85 \%$ and brain injury by $88 \%{ }^{14}$ Despite the burden of illness due to these injuries, and available preventive measures, many jurisdictions or countries, including Manitoba, have been slow to adopt a coordinated approach to bicycle injury prevention. To evaluate the need for a large community based safety campaign, we initiated a helmet observation study. The purpose of this study was to document current helmet use in Winnipeg (Manitoba's largest city, with half of the provincial population) and in nearby rural communities, and to identify groups more resistant to helmet use for a future preventive campaign.

\section{Methods}

SUBJECT AND SITE SELECTION

The subjects were all cyclists observed between 28 May and 20 August 1996 at 190 urban sites in the City of Winnipeg and in 30 nearby rural communities. Urban sites included both inner city and suburban areas within Winnipeg. Rural communities were small to medium sized towns situated in agricultural settings. Cyclists of all ages and both sexes were included and were categorized by observation without stopping them for verification. This 
study was conducted concurrently with an in-line skater observational study. ${ }^{20}$

Observations were made at five types of locations: parks, schools, residential streets, major intersections, and a few cycling paths. Approximately equal numbers of the first four types were selected.

In Winnipeg, 40 schools and 40 parks were randomly selected from sampling frames of all elementary schools and all city operated public parks. For major intersections and residential street locations, a map portraying the city's 190 characterized neighbourhoods was used. Neighbourhoods without a school or park already assigned (110) were alternately assigned to residential street or major intersection (55 each). The city map was divided into six zones to check that a balanced distribution of all location types had occurred throughout all zones.

Rural site locations were determined by drawing a $60 \mathrm{~km}$ radius from the centre of Winnipeg on a map and dividing the area into quadrants. The largest towns in each quadrant were purposefully selected, and smaller communities were chosen at random. Two observation sites were assigned within the two largest towns, while in all others, either a school, park, residential street, or major intersection was chosen on the basis of the highest expected cycling traffic. In many communities, the only park was located at its school.

DATA COLLECTION

A single, trained observer conducted all observations. Training was done by an experienced research nurse from IM-PACT (Injuries Manitoba-Prevention of Adolescent and Childhood Trauma) and a cycling instructor from the Manitoba Cycling Association. A minimum of 20 minutes, and a maximum of 60 minutes, was spent at each site. One third of the observations were done on weekends and one sixth were scheduled for the early evening. To minimize the possibility of duplicating observations, the observer chose different areas of the city on consecutive days. Observations were made in all weather conditions. Site location, date, and site characteristics were recorded. No formal reliability check was performed.

For each cyclist, information was collected on age, gender, helmet use, and riding companions (riding alone, with adults, children, or both). Additionally, whether helmets were worn correctly and whether headphones were used were observed. Correct helmet use was ascertained by visually assessing fit, positioning on the head, and appropriate strap use. The observer was trained to assess correct fit by the cycling instructor.

DATA ANALYSIS

Field data were entered into a database created in Microsoft Access. The prevalence of helmet use (with $95 \%$ confidence intervals, CI) was determined overall and for subgroups of interest. Subgroups were described by the variables age, sex, rural or urban residence, location type (school, park, major intersection, residential street, or cycling path), riding companion (adult, child, or both), and neighbourhood income (urban only). The latter was done by cross referencing each site to a City of Winnipeg map that displayed the median neighbourhood income of Winnipeg's 190 neighbourhoods by income strata. ${ }^{21}$

A univariate analysis was carried out for all variables by creating contingency tables and calculating $\chi^{2}$ values for each comparison. A Mantel-Haenszel trend test was used to relate helmet use to median neighbourhood income. A multivariate analysis was then done. For each of the five age categories, a separate backwards stepwise logistic regression was run because we wanted to know the age specific influence of each variable so as to best plan for targeted promotion strategies. Adjusted odds ratios with $95 \%$ CI were calculated from the final models.

Due to cells with small numbers, some collapsing of categories was necessary for the logistic regression analysis. For children: children riding with adults and those riding with adults and children were combined; the lowest two income strata were combined; and riding on cycling paths was combined with riding in parks. For older teens (age 16-19): very low income, low income, and rural were combined. For adults: adults riding with children and those riding with adults and children were combined.

\section{Results}

Cyclists were observed for helmet use at 220 sites in Manitoba: 190 in the City of Winnipeg, and 30 in nearby rural communities. At 12 sites no cyclists were observed. The remaining 208 locations (183 city and 25 rural) yielded 2629 observations, including 1286 children and 1343 adults; 1844 were male, 772 were female, and 13 were of unknown gender. (The latter subjects were excluded for the gender and multivariate analysis, but were included for the remaining analyses.)

The total prevalence of helmet use was $21.3 \%$ (95\% CI $19.7 \%$ to $22.8 \%$ ). For all ages combined, the prevalence of helmet use in males $(18.9 \%$, $95 \%$ CI $17.1 \%$ to $20.7 \%)$ was significantly lower than in females $(26.3 \%$, $95 \%$ CI $23.2 \%$ to $29.4 \%)\left(\chi_{(1)}^{2}=18.0\right.$, $\mathrm{p}<0.0001)$. Table 1 shows helmet use by age, and fig 1 shows helmet use by age and gender. The highest prevalence was in children less than 8 years old and in adults, and the lowest use was observed in teenagers $\left(\chi_{(4)}^{2}=178.6\right.$, $\mathrm{p}<0.0001)$.

Table 1 Prevalence of helmet use by age

\begin{tabular}{llll}
\hline $\begin{array}{l}\text { Age group } \\
\text { (years) }\end{array}$ & No observed & $\begin{array}{l}\text { No (\%) } \\
\text { wearing } \\
\text { helmets }\end{array}$ & $95 \%$ CI (\%) \\
\hline$<8$ & 319 & $140(43.9)$ & 38.4 to 49.3 \\
$8-11$ & 312 & $52(16.7)$ & 12.5 to 20.8 \\
$12-15$ & 439 & $32(7.3)$ & 4.9 to 9.7 \\
$16-19$ & 216 & $18(8.3)$ & 4.6 to 12.0 \\
$>19$ (adult) & 1343 & $317(23.6)$ & 21.3 to 25.9 \\
Total & 2629 & $559(21.3)$ & 19.7 to 22.8 \\
\hline
\end{tabular}




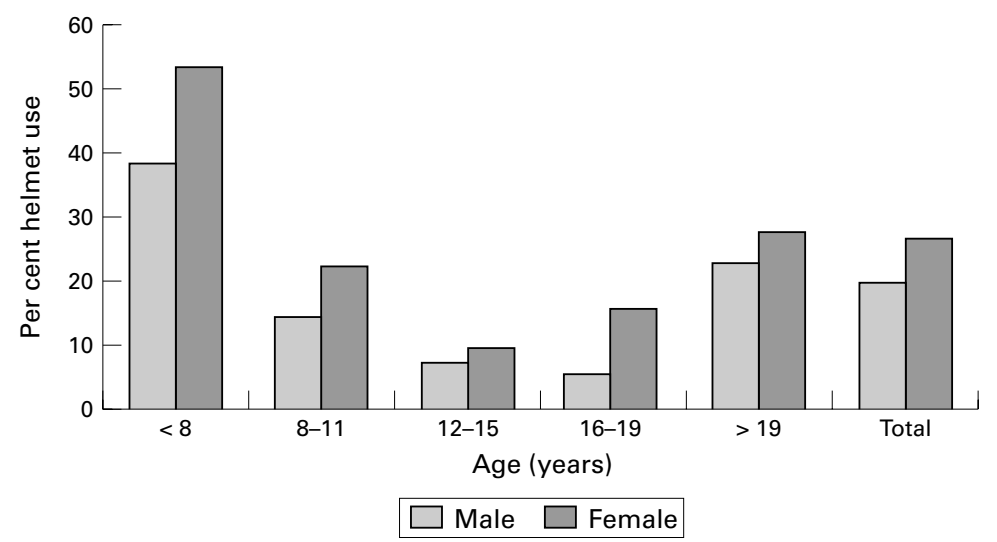

Figure 1 Prevalence of helmet use by age and sex.

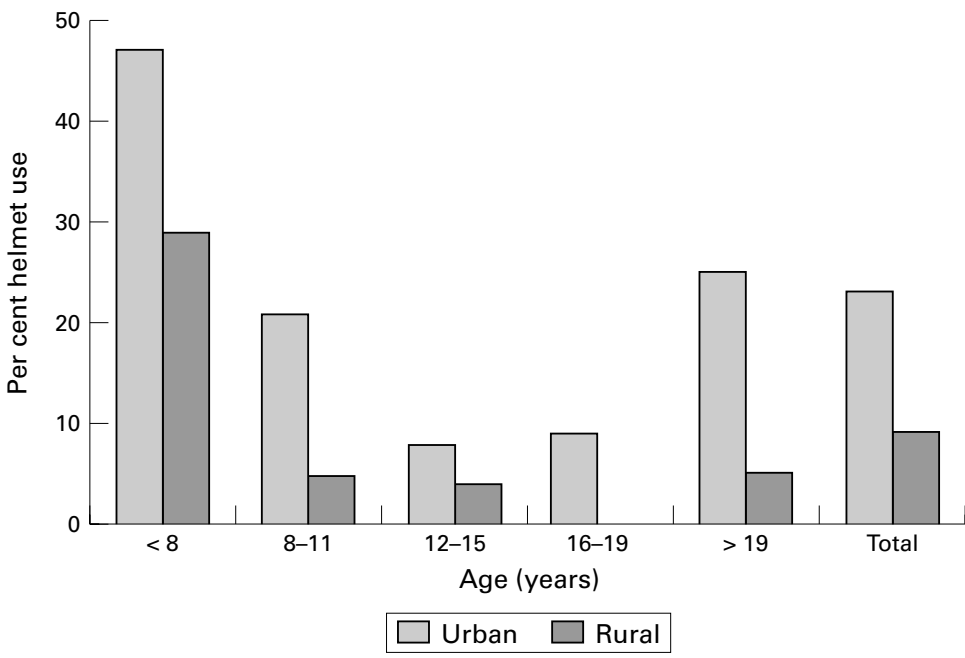

Figure 2 Urban v rural helmet use by age.

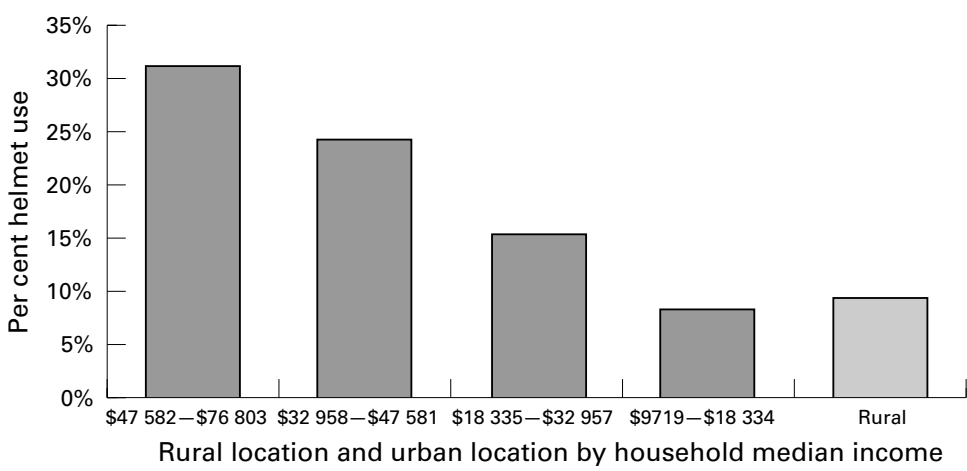

Figure 3 Prevalence of helmet use by urban income and rural status.

There was a highly significant difference $\left(\chi_{(1)}^{2}=32.2, \mathrm{p}<0.0001\right)$ between the urban rate (Winnipeg) $22.9 \%$ (95\% CI $21.2 \%$ to $24.6 \%$ ) compared with the rate in rural locations $8.9 \%$ (95\% CI $5.8 \%$ to $12.1 \%$ ) (fig 2 ). Figure 3 shows the prevalence of rural helmet use in comparison with urban use by urban income levels. Urban helmet use was directly related to income: in the highest income area it was $30.5 \%$ ( $95 \%$ CI $26.7 \%$ to $34.2 \%$ ) and $7.8 \%$ ( $95 \%$ CI $3.4 \%$ to $12.2 \%$ ) in the lowest. (In the lowest income area (\$9719-\$18 334), 55\%$85 \%$ of all households live below the poverty line. ${ }^{21}$ ) A Mantel-Haenszel trend test was highly significant for the four income strata $(p=0.0001)$. Although the urban prevalence was significantly higher than the rural prevalence, the low income urban prevalence was similar to the rural rate.

The multivariate analysis examined the explanatory effects of gender, location (urban or rural), income (urban only), location type, and riding companion on the rate of use within each of the five age categories. The results are summarized in table 2 .

For the "under 8" age category, median neighbourhood income below $\$ 32958$, riding rurally, and male sex were predictive variables for lower helmet use. For this analysis, the lowest income level (\$9719-\$18 334) was combined with the next highest level because no children (out of 28 observed aged 19 or younger) were wearing helmets in the lowest income area. The location type, and riding with one or more adult (compared with riding with other children or alone), were not significant variables.

For the 8-11 year old group, sex was not a significant explanatory variable. Riding rurally, and riding in a neighbourhood with median income below $\$ 32958$, were predictive variables for lower helmet use. Riding with one or more adult, and riding in a park (compared with all other locations), were protective against lower helmet use.

For young teenagers (age 12-15 years), riding with one or more adult was the only significant explanatory variable protective against lower helmet use. However, this was based on small numbers: only 18 cyclists in this age group were observed riding with adults. Sex, neighbourhood income, location type, and riding rurally were not significant variables.

For older teens (age 16-19), the combined variable low income/rural was significant compared with higher income urban groups in predicting lower helmet use. Riding with an adult was protective against lower helmet use, although this was also based on small numbers: 15 cyclists in this age group were observed riding with adults. Gender and location types were not significant.

For adults, four out of the five variables examined were significantly predictive regarding helmet use. Median neighbourhood income was highly significant; all three of the lower income strata predicted lower helmet use compared with the highest strata. Riding rurally was also significant, as was male sex, in predicting lower helmet use. Riding near a major intersection was protective against lower helmet use.

The prevalence of incorrect helmet use by age is shown in table 3 . Total incorrect use was $9.3 \%$, with children showing higher rates of errors than adults. The most common error was having the helmet positioned too far back on the head $(65 \%)$. Other errors noted were: incorrect use of straps (27\%), helmet too far forward $(6 \%)$, and wrong size of helmet $(2 \%)$. Forty three riders were observed wearing headphones while cycling; all were 12 or older, and most (40) were over 15. 
Table 2 Multivariate analysis - significant variables predictive of lower helmet use by age categories

\begin{tabular}{|c|c|c|c|}
\hline $\begin{array}{l}\text { Age } \\
\text { group } \\
\text { (years) }\end{array}$ & Significant variables & $\begin{array}{l}\text { Adjusted odds } \\
\text { ratios ( } 95 \% \text { CI) }\end{array}$ & Non-significant variables* \\
\hline \multirow[t]{5}{*}{$<8$} & Lower income & $5.0(2.2$ to 11.5$)$ & Riding near a school \\
\hline & Riding rurally & $2.3(1.3$ to 4.3$)$ & Riding in a park \\
\hline & Sex (male) & $1.9(1.2$ to 3.0$)$ & $\begin{array}{l}\text { Riding near major } \\
\text { intersection }\end{array}$ \\
\hline & & & $\begin{array}{l}\text { Riding with other } \\
\text { children }\end{array}$ \\
\hline & & & Riding with adult(s) \\
\hline \multirow[t]{4}{*}{$8-11$} & Riding rurally & $5.4(1.8$ to 16.1$)$ & $\begin{array}{l}\text { Riding near major } \\
\text { intersection }\end{array}$ \\
\hline & Lower income & $5.4(1.1$ to 26.3$)$ & $\begin{array}{l}\text { Riding with other } \\
\text { children }\end{array}$ \\
\hline & Riding in a park & $0.39(0.17$ to 0.90$)$ & Riding near a school \\
\hline & Riding with adult(s) & $0.14(0.05$ to 0.38$)$ & Sex \\
\hline \multirow[t]{7}{*}{$12-15$} & Riding with adult(s) & $0.25(0.08$ to 0.81$)$ & Income \\
\hline & & & Riding near a school \\
\hline & & & Sex \\
\hline & & & $\begin{array}{l}\text { Riding with other } \\
\text { children }\end{array}$ \\
\hline & & & $\begin{array}{l}\text { Riding near major } \\
\text { intersection }\end{array}$ \\
\hline & & & Riding in a park \\
\hline & & & Riding rurally \\
\hline \multirow[t]{4}{*}{$16-19$} & Riding rurally/lower income & $6.5(1.7$ to 24.4$)$ & Riding in a park \\
\hline & Riding with adult(s) & $0.20(0.05$ to 0.92$)$ & $\begin{array}{l}\text { Riding with other } \\
\text { children }\end{array}$ \\
\hline & & & $\begin{array}{l}\text { Riding near major } \\
\text { intersection }\end{array}$ \\
\hline & & & Riding near a school \\
\hline \multirow[t]{6}{*}{$>19$} & Riding rurally & $12.1(4.3$ to 34.5$)$ & $\begin{array}{l}\text { Sex } \\
\text { Riding on cycling path }\end{array}$ \\
\hline & Income $\$ 9719-\$ 18334$ & $6.1(3.1$ to 11.8$)$ & Riding with other adults \\
\hline & Income $\$ 18335-32957$ & $2.9(2.1$ to 4.1$)$ & Riding in a park \\
\hline & Income $\$ 32958-47581$ & $2.0(1.5$ to 2.9$)$ & Riding with children \\
\hline & Sex (male) & $1.4(1.1$ to 1.9$)$ & Riding near a school \\
\hline & Riding near a major intersection & $0.61(0.46$ to 0.80$)$ & \\
\hline
\end{tabular}

*Variables listed in order of being dropped from the stepwise logistic regression analysis.

Table 3 Prevalence of incorrect helmet use by age

\begin{tabular}{llll}
\hline $\begin{array}{l}\text { Age } \\
\text { group (years) }\end{array}$ & $\begin{array}{l}\text { No } \\
\text { observed } \\
\text { wearing }\end{array}$ & $\begin{array}{l}\text { No (\%) } \\
\text { wearing } \\
\text { incorrectly }\end{array}$ & $95 \%$ CI (\%) \\
\hline$<8$ & 140 & $24(17.1)$ & 10.9 to 23.4 \\
$8-11$ & 52 & $8(15.4)$ & 5.6 to 25.2 \\
$12-15$ & 32 & $8(25.0)$ & 10.0 to 40.0 \\
$16-19$ & 18 & $2(11.1)$ & 0.0 to 25.6 \\
$>19$ & 317 & $10(3.2)$ & 1.2 to 5.1 \\
Total & 559 & $52(9.3)$ & 6.9 to 11.7 \\
\hline
\end{tabular}

\section{Discussion}

The current prevalence of helmet use in our region $(21.3 \%)$ is comparable with "baseline" rates in communities in other countries and elsewhere in Canada before promotional efforts $(<20 \%){ }^{22-25}$ It is considerably below helmet use rates elsewhere obtained following promotional campaigns and/or legislation. ${ }^{18} 1923$ This relatively low prevalence points to an urgent need for a population helmet promotion strategy in our area.

The pattern of helmet use by age groups described in this study is consistent with the findings of others. ${ }^{23-26} 28-31$ Specifically, teens are least likely to wear helmets compared with both younger children and adults. This study confirmed that teens are an important target group in our area. Similarly, the finding of higher helmet use by females than males is consistent with other studies. ${ }^{2325263132}$

The marked difference found between urban $(22.9 \%)$ and rural $(8.9 \%)$ helmet use has not previously been described. Rural helmet use was lower than urban use across all age groups and for both sexes. Although rural cycling may be perceived as safer than urban cycling, hospitalization data indicate that bicycle related hospitalization is somewhat higher for rural than urban children (unpublished data, Epidemiology Unit, Manitoba Health and Health Information Systems, Manitoba Health). This study has identified the need for helmet promotion to target rural cyclists, as well as further research into rural cycling practices and attitudes.

The trend in helmet use relative to median neighbourhood income is consistent with that described in other cities. In Toronto, helmet use was two to three times greater in high income areas for combined school and recreational sites $(29 \% v 12 \%){ }^{32} \mathrm{~A}$ follow up survey in Seattle found a difference between low and high income areas (31.6\% v 44.4\%), although no difference had been found on the baseline study ${ }^{18}$ In Winnipeg, the nearly fourfold difference in helmet use between the highest $(30.5 \%)$ and lowest $(7.8 \%)$ income neighbourhoods is alarming. Possible factors underlying this finding, such as cost barriers, availability, and attitudes, warrant further study. A special focus on low income urban areas should be included in a helmet promotion strategy.

Generally, helmet use did not vary with site type on univariate analysis (school, park, major intersection, residential street, cycling path), whereas other studies found such differences. A study in Toronto reported higher helmet use at schools than at recreational sites in high income areas for both control and intervention groups. ${ }^{32}$ Conversely, in an Ottawa study, recreational cyclists (cycling on bike paths or parkways during weekends) had higher helmet usage than students observed arriving or leaving school. ${ }^{30}$ In the latter study, school aged recreational cyclists are believed to have represented a higher income group than students cycling to school. In Winnipeg, the various site types (other than cycling paths) had balanced representation from all income strata due to the sampling method. Few cycling paths were observed, as few exist in Winnipeg, which limited the analysis of helmet use on cycling paths. The school sampling frame was limited to elementary schools, and this may have inflated helmet use observed at school locations by selecting a higher proportion of younger riders.

The multivariate analysis for each age category elicited some interesting findings. Gender as an independent variable was found to be significant for very young riders (under 8 years) and adults (with males being less likely to wear helmets), but gender was not predictive for older children or teens. The gender difference is particularly interesting in young riders, as parental input to decision making is likely to be high. Two possible explanations could be that parents have different attitudes towards protective equipment for girls than boys, or that helmet refusal is higher in boys than girls. Understanding this difference may help to establish improved lifelong helmet practices for boys. It was interesting that gender was not significant for older children and teens where helmet use is lowest. Possibly, gender difference could not be detected due to 
low rates of use, or perhaps other factors are simply more important in this age group. The implication to consider for promotion is that marketing endeavors for young children and adults (especially parents) should specifically target males, while strategies for older children and teens must equally engage males and females.

Riding rurally was significant on multivariate analysis for all groups except $12-15$ year olds, although the analysis of 16-19 year olds was based on a combined variable of low income/ rural location. This supports the need for targeting rural helmet promotion throughout the age spectrum. For young teenagers (12-15 years) no variables other than riding with one or more adult was significant. Age alone seems to be the most important predictive variable for teenagers aged $12-19$ years, and age $12-15$ in particular.

Regarding the riding companion variable, riding with an adult was a significant predictive variable for increased use in all age groups under 20 (except under 8, which narrowly missed attaining significance). It was initially planned to further analyze the predictive value of riding with a helmet wearing companion, particularly an adult. However, the number of children riding with adults was too few to permit this subanalysis. Accompaniment by at least one cycling adult occurred only $12 \%$ of the time for the youngest group (under 8), and only $7 \%$ of the time for all children (although accompaniment on foot was not recorded). This finding may warrant further exploration in future studies, as more adult involvement would seem desirable for the supervision and training of young riders, in addition to the modeling of helmet use.

It seems reasonable to conclude that in our population at least, children riding with adults are more likely to wear helmets, although as noted, this analysis was based on small numbers. This is consistent with findings elsewhere. ${ }^{183132}$ A possible explanation is that families valuing helmet use for children also value supervision. However, the usefulness of this finding in a promotion campaign is limited, because assessing the influence of adult modeling of helmet use was not possible. Studies in other locations have found that children are more likely to wear helmets if riding with others wearing helmets, whether adults or children. ${ }^{18} 273132$

For the location variable, riding near major intersections was predictive of higher helmet use in adults. This likely indicates the tendency towards higher helmet use by commuting cyclists who may take personal protection more seriously when riding regularly for transportation. The 8-11 year old group was the only childhood subgroup for which riding location was significantly predictive, where riding in a park (compared with all other locations) predicted greater helmet use. Unfortunately, this finding has little practical application in the development of a promotion campaign.

Riding in a lower income neighbourhood was predictive for lower helmet use on multivariate analysis in all but the $12-15$ year age category (with the analysis of 16-19 year olds using a combined low income/rural location variable as mentioned above). Particularly concerning was that the lowest two income categories had to be collapsed for the multivariate analysis because no helmeted children or teens were observed in the lowest income areas. While this is based on small numbers (only 28 cyclists under 19 years observed), further attention to helmet use by children in very low income neighbourhoods seems warranted.

Incorrect helmet use was observed in 52 of the 559 helmeted cyclists $(9.3 \%)$. This is much lower than documented in a Sudbury study where $51 \%$ of helmeted riders were found to have a helmet wearing error. ${ }^{24}$ However, in Sudbury, riders were stopped and fit was tested, whereas our study noted observed fit errors only. Therefore, our findings likely under-represent true fit errors. The most common errors observed were positioning of the helmet too far back and using straps incorrectly. This highlights specific helmet fit issues to include in a promotion strategy. It also warrants consideration by helmet manufacturers, as many helmet designs do not ensure that straps hold well in adjusted positions. Excessive strap mobility may lead to improperly adjusted straps and positioning of the helmet too far back, particularly in children who are not likely to readjust straps before each use and may handle helmet straps roughly. This is particularly relevant because children had a higher proportion of incorrectly fitting helmets than adults.

The finding of 43 riders using headphones while riding may indicate an emerging safety issue for cyclists. The increasing popularity of headphones among teenagers and young adults may become problematic if use while cycling becomes widespread. Including this issue in a helmet promotion initiative may prevent a large scale problem from developing. This issue has not been addressed in other studies.

A limitation to this study was the small sample size, particularly the smaller number of rural observations made in comparison to urban observations. This lead to small cell numbers for some of the subgroup analyses. As mentioned, the sample size was not large enough to evaluate the effect of helmet use by riding companions in predicting helmet use.

While the use of a single observer safeguarded against inconsistent observations to a degree, the internal validity would have been strengthened by conducting reliability checks. Finally, assessing age, gender, and helmet fit by observation alone likely resulted in some misclassification error.

\section{Implications for prevention}

Cycling is a healthy, environmentally friendly, and enjoyable activity. However, the positive benefits of cycling should be framed within the context of safety. Because helmet use is known to be effective in reducing serious head and other injuries from cycling mishaps, helmet 
promotion should be a key part promoting cycling safety.

This study documented a low prevalence of helmet use in our area relative to much higher rates attained in other communities. This suggests that helmet promotion is urgently needed in our community. Groups with exceptionally low rates of helmet use were identified. This should assist in developing promotional strategies. These include rural cyclists, cyclists in lower income neighbourhoods, males (young boys and adults in particular), and teens (aged 12-19 years). Before developing a campaign to target these risk groups, it would be helpful to examine the barriers to helmet use for each target group. Attitudes, access (cost), and other issues could be explored in focus group discussions. ${ }^{33}$ Given our findings, a multifaceted approach addressing the issues raised would be recommended.

Promotion campaigns and legislation have been shown to be effective in increasing helmet use. This survey provides evidence to justify the pursuit of an educational campaign, followed by lobbying for helmet legislation in Manitoba. This study also provides useful baseline data to allow evaluation of the effectiveness of future helmet promotion endeavors.

This work was supported in part by IM-PACT and CareerStart '96. The authors gratefully acknowledge the contributions of ole Heppenstall for assistance with data entry.

1 Markesteyn P. Annual reviews, 1991-1995. Winnipeg: Office of the Chief Medical Examiner, Manitoba, 1991-1995.

2 Armson CJ, Pollard CW. Child cyclist injuries: a prospective study. Med f Aust 1986;144:144-6.

3 Baker SP, Li G, Fowler C, et al. Injuries to bicyclists: a national perspective. Baltimore, Maryland: John Hopkins University Injury Prevention Center, 1993.

4 Cushman R, Down J, MacMillan N, et al. Bicycle-related injuries: a survey in a pediatric emergency department. Can Med Assoc F 1990;143:108-12.

5 Friede AM, Azzara CV, Gallagher S, et al. The epidemiology of injuries to bicycle riders. Pediatr Clin North Am 1985;32 $141-51$.

6 Illingworth CM, Noble D, Bell D, et al. 150 bicycle injuries in children: a comparison with accidents due to other causes. Injury 1981;13:7-9.

7 Moyes CD, Tustin RJ, McCallum PL, et al. Injuries to child cyclists in the Bay of Plenty. N Z Med f 1990;103:343-5.

8 Selbst SM, Alexander D, Ruddy R. Bicycle-related injuries. Selbst SM, Alexander D, Ruddy
Am Dis Child 1987;141:140-4.

9 McKenna PJ, Welsh DJ, Martin LW. Pediatric bicycle trauma. F Trauma 1991;31:392-4.
10 Cass DT, Gray AJ. Pediatric bicycle injuries. Aust NZ $Z$ Surg 1989;59:719-24.

11 Nakayama DK, Gardner MJ, Rogers KD. Disability from bicycle-related injuries in children. $\mathcal{F}$ Trauma 1990;30: $1390-4$

12 Nakayama DK, Pasieka KB, Gardner MJ. How bicyclerelated injuries change bicycling practices in children. Am $\mathcal{F}$ Dis Child 1990;144:928-9.

13 Thorson J. Pedal cycle accidents. Scand f Soc Med 1974;2:121-8.

14 Thompson RS, Rivara FP, Thompson DC. A case-control study of the effectiveness of bicycle safety helmets. N Engl F Med 1989;320:1361-7.

15 Thompson DC, Thompson RS, Rivara FP, et al. A case-control study of the effectiveness of bicycle safety helmets in preventing facial injury. Am $\mathcal{f}$ Public Health 1990;80:1471-4.

16 McDermott FT, Lane JC, Brazenor GA, et al. The effectiveness of bicyclist helmets: a study of 1710 casualties. 7 Trauma 1993;34:834-45.

17 Thompson DC, Rivara FP, Thompson RS. Effectiveness of bicycle safety helmets in preventing head injuries. $\mathscr{f} A M A$ 1996;276:1968-73.

18 Rivara FP, Thompson DC, Thompson RS, et al. The Seatle children's bicycle helmet campaign: changes in helmet use and head injury admissions. Pediatrics 1994;93:567-9.

19 Mock CN, Maier RV, Boyle E, et al. Injury prevention strategies to promote helmet use decrease severe head injuries at a level I trauma center. $\mathcal{F}$ Trauma 1995;39:29-35.

20 Warda L, Harlos S, Klassen TP, et al. An observational study of protective equipment use among inline skaters. Inj Prev 1998;4:198-202.

21 Social Development Review Committee, City of Winnipeg. Planning for equity in Winnipeg. Winnipeg: City of Winnipeg, 1996.

22 Cushman R, Down J, MacMillan N, et al. Bicycle helmet use in Ottawa. Can Fam Physician 1990;36:697-700.

23 Morris BAP, Trimble NE, Fendley SJ. Increasing bicycle helmet use in the community: measuring response to a wide-scale, 2-year effort. Can Fam Physician 1994;40: $1126-31$

24 Rowe BH, Thorsteinson K, Bota GW. Bicycle helmet use and compliance: a Northeastern Ontario roadside survey. Can F Public Health 1995;86:57-61.

25 Farley C, Haddad S, Brown B. The effects of a 4-year program promoting bicycle helmet use among children in Quebec. Am $\mathcal{F}$ Public Health 1996;86:46-51.

26 Rourke LL. Bicycle helmet use among schoolchildren: impact of a community education program and a cycling fatality. Can Fam Physician 1994;40:1116-24.

27 Coté TR, Sacks JJ, Lambert-Huber DA, et al. Bicycle helmet use among Maryland children: effect of legislation and education. Pediatrics 1992;89:1216-20.

28 Vulcan AP, Cameron MH, Watson WL. Mandatory bicycle helmet use: experience in Victoria, Australia. World 7 Surg 1992;16:389-97.

29 Weiss BD. Trends in bicycle helmet use by children: 1985 to 1990. Pediatrics 1992;89:78-80.

30 Cushman R, Pless R, Hope D, et al. Trends in bicycle helmet use in Ottawa from 1988 to 1991. Can Med Assoc F 1992; 146:1581-5.

31 DiGuiseppi CG, Rivara FP, Koepsell TD, et al. Bicycle helmet use by children: evaluation of a community-wide helmet campaign. $尹 A M A$ 1989;262:2256-61.

32 Parkin PC, Spence LJ, Hu X, et al. Evaluation of a promotional strategy to increase bicycle helmet use by children. Pediatrics 1993;91:772-7.

33 Howland J, Sargent J, Weitzman M, et al. Barriers to bicycle helmet use among children. Results of focus groups with fourth, fifth and sixth graders. Am 7 Dis Child 1989;143: $741-4$. 